\title{
Submissions Style Guide for the Global Clinical Engineering Journal
}

\section{By J.S. Schultz' and Y. David ${ }^{2}$}

${ }^{1}$ Department of Biomedical Engineering, University of Houston, Houston, Texas, USA.

${ }^{2}$ Biomedical Engineering Consultants, LLC, Houston, Texas, USA.

\begin{abstract}
This paper provides guidelines for writing an effective manuscript that complies with the general scientific writing style. In particular, these guidelines are used by the editors and reviewers of the Global Clinical Engineering Journal (www. GlobalCE.org) when they evaluate submitted manuscripts. Readers of this paper will gain an understanding of the preferred writing format for each of the manuscript's individual sections. Examples are provided that illustrate their purpose and presentation style for each section. We expect the guidance provided in this paper to improve the quality of writing in general but especially by young clinical engineers so that their published work will attract the interest of the general scientific community.

Keywords - Clinical engineering, Paper, Manuscript, Scientific paper, submission, journal, global ce, global, write, technical writing, abstrcat, conclusion, methodology, results, methods, review, guide, conclusions.

Copyright (c) 2021. This is an open-access article distributed under the terms of the Creative Commons Attribution License (CC BY): Creative Commons - Attribution 4.0 International - CC BY 4.0. The use, distribution or reproduction in other forums is permitted, provided the original author(s) and the copyright owner(s) are credited and that the original publication in this journal is cited, in accordance with accepted academic practice. No use, distribution or reproduction is permitted which does not comply with these terms.
\end{abstract}

\section{INTRODUCTION}

Publications and distribution of research work and of best practices in the field of clinical engineering remain highly limited. This is particularly the case for young beginning researchers in the healthcare technology management area. Yet, writing a scientific manuscript is arguably the most important step in the development and preservation of knowledge. ${ }^{1}$ Nevertheless, few authors have been taught how to effectively communicate and to professionally write manuscripts. In addition, they struggle with selecting the most suitable writing style and the best way to present their data. ${ }^{2}$ Writing styles vary according to the purpose of the paper and the intended audience. For example, the format for a newspaper article is vastly different than for a scientific journal. Even within the scientific journal domain, there are different styles for research accounts, review papers, editorials, and letters to the editor. Because readers are accustomed to a certain style in the different domains, using the conversation-like style of a letter in a scientific paper can put off the reader. Clinical engineering authors may be challenged to identify and use the optimal visual medium to use to report on their work results and processes. For example, finding the optimal way to share data that lends itself more to a presentation using graphical or tabulated formats. ${ }^{3}$

\section{METHODS}

Aside from some minor variations, the structure and organization of most scientific manuscripts follow a simple format: Introduction, methods, results, discussion, conclusions, and references. ${ }^{4}$ Writing a manuscript, 
especially for a peer-reviewed journal like Global Clinical Engineering Journal (http://www.globalce.org/downloads/ Guidelines\%20to\%20Authors_final.pdf) demands work that may seem like a burden within the clinical engineering community. But there are good reasons to persevere. Knowledge grows and advances through sharing, supporting, and challenging information. It also contributes to the author's expertise and career advancement. Basically, authors are expected to write accurately, clearly, and succinctly. Here, we provide some guidelines for submitting research articles in this journal.

The basic format for manuscripts submitted for consideration by the reviewers for this journal is outlined below:

1. Title Section

2. Authors and their Affiliations

3. Abstract Section

4. Introduction Section

5. Methods Section

6. Results Section

7. Discussion and Conclusions Section

8. References Section

In this paper, we will provide some guidance and suggestions for successfully getting your message to your audience.

\section{Title Section}

The choice of words for the title of the paper is quite important. The title is the first piece of information that can catch the attention of reviewers as well as prospective readers. The title should be concise and should reflect the content and impact of your study.

\section{Title Example 1.}

"Progressing Toward the Application of Artificial Intelligence for Medical Equipment Replacement in Canadian Hospitals - An Idea from the Biomedical Engineering Department at Northern Health" ${ }^{5}$

This title might be better stated as:

"Artificial Intelligence Methods for Medical Equipment Replacement Decisions"

\section{Title Example 2.}

"Benchmarking Comparison Between Beijing and American Hospitals"6
This title might be better stated as:

"Comparison of Beijing and American Hospitals in Operations, Finance, and Staffing/Productivity"

\section{Title Example 3.}

"Pulse Spectrophotometric Determination of Plasma Bilirubin in Newborns" ${ }^{7}$

Might be better stated as:

"Plasma Bilirubin Determination in Newborns by Plus Spectrophotometry"

Lang $^{1}$ gives the following list of items to consider for titles of public health type articles:

(I) the study setting, location, or both;

(II) the patients, organism, event, or relationship studied;

(III) the intervention, treatment, or exposure;

(IV) the comparator or control group(s);

$(V)$ the outcomes or end points;

(VI) the study design, and sometimes;

(VII) the time period or duration of the study.

For example, suppose an investigation has the following characteristics. Any of them can impact the selection of an appropriate title:

\section{A long title might be:}

"Effectiveness of 'Smart Toilets' Using Ultraviolet Germicidal Irradiation vs. Regular Cleaning for Reducing Escherichia coli Infections in Refugee Settlements in Jordan: A Randomized Trial"

\begin{tabular}{|l|l|}
\hline Study characteristics & Potential impact of title selection \\
\hline the setting and location: & refugee settlements in Jordan \\
\hline the patients or subjects: & residents using public toilets \\
\hline the intervention: & $\begin{array}{l}\text { self-disinfecting "smart toilets" } \\
\text { using ultraviolet irradiation to kill } \\
\text { bacteria }\end{array}$ \\
\hline the control condition: & regular manual toilet cleaning \\
\hline the end point: & Escherichia coli infections \\
\hline the study design: & randomized trial \\
\hline the time period & (probably not a factor in this study) \\
\hline
\end{tabular}




\section{A short title instead might be:}

"Effectiveness of Self-Disinfecting Toilets for Reducing Escherichia coli Infections"

\section{Authors and their Affiliations}

The author's names will be published exactly as they appear in the accepted article. It should not include titles such as Dr., or Professor, or Ph.D. One of the early considerations by readers of the published articles is reviewing the author or authors and their affiliations. Each author usually will have at least one or more affiliations. Affiliation means the association of the author with an organization or a group. Noted affiliations usually suggest a relationship between the article work and the location where the work conducted, support was provided, or the tools used were located. Affiliations will be published as they appear in the accepted manuscript. Include each component of the affiliation information in order of small to large (Department, Division, Section, Institution, City, State, Country). Do not include ZIP or Postal Codes, street addresses, or building/office numbers. There is also no need to list positions within an institution (e.g., Department Chair, Professor, etc.). Consider the designation of the corresponding author for future communications, but do not include physical addresses; only an e-mail address is required. You can list the corresponding author's initials in parentheses following the email address. The corresponding author should be indicated with the placement of an asterisk after the name, and be written corresponding with the author's e-mail below the first page of the manuscript. The asterisk shall be omitted if there is only one author.

You are, as an author, expected to review this carefully as names and affiliations may be automatically corrected and modified with various editing apps.

\section{Abstract Section}

The Abstract section is one of the most important parts of a published article. After the title, it is the section that an individual reads or scans to decide whether to look at the full paper. It is essential that authors be very careful that the abstract is consistent with the rest of the manuscript. Studies have shown that many abstracts do not reflect the content of the report in the methods, results, or conclusions. ${ }^{8,9}$
The abstract should contain the following information. ${ }^{10}$ Highlights of an abstract include:

a. An introduction of the topic

b. A brief mention of the important methods or techniques that were used in the report

c. The most significant results of the report

d. A succinct summary of the conclusions

The following is an example of an abstract with too much detail (about 425 words). ${ }^{6}$

"The first clinical engineering (CE) benchmarking between Chinese and American hospitals was performed in 2014. At that time, only data from Zhejiang province were available. A new comparison was completed in 2018 with data collected from 11 hospitals from the capital city of Beijing. These data were compared with those from 270 acute care hospitals in the United States. First, comparisons were made with hospital data such as patient discharges, patient days, equipment quantity and cost, and operating costs. The CE benchmarking comparison was made in 3 categories: (a) operations, (b) finance, and (c) staffing/productivity. Within the operations category, the following metrics were compared: equipment amount/operating beds, annual repairs/equipment amount, and annual scheduled maintenance/equipment amount. Within the finance category, the following metrics were compared: total CE expense/total hospital operating expense, total CE expense/operating beds, and total CE expense/equipment cost. Within the staffing/productivity category, the following metrics were compared: total CE fulltime equivalent (FTE)/equipment amount, total CE FTE/operating beds, and total CE FTE/total hospital operating expense. These comparisons showed the following: (1) Although still a bit lower than the United States, Beijing hospitals have more equipment than Zhejiang but a slightly lower amount of repairs and scheduled maintenance per equipment; (2) the total CE expense/total hospital operating expense ratio is around 1\% in both Beijing and the United States, but slightly greater than in Zhejiang; however, the total CE expense/operating beds and total CE expense/ equipment cost are still lower in Beijing and Zhejiang than in the United States; and (3) the CE FTE amount is lower in Beijing than in Zhejiang and closer to the 
United States relative to both equipment amount and total hospital operating expense, but still a bit lower than the United States relative to the number of operating beds. Some of the differences detected are likely caused by the same factors found in the previous study of Zhejiang hospitals, namely, higher length of stay in China than in the United States, lower wages and living costs in China, and different healthcare delivery methods in these countries. The differences found between Beijing and Zhejiang cannot be explained solely by inflation ( $2 \%$ /year) or even higher cost of living in the capital but likely because of more equipmentintensive medical practice. Overall, these results confirm the outstanding progress and level of excellence of CE in China. The original abstract includes information concerning Zhejiang province, but the main focus of the paper is the comparison between Beijing and the United States. So, references to Zhejiang were removed from the abstract."

The abstract should follow the journal author's guidelines. The guidelines for the Global CE Journal can be found on the journal website (http://www.globalce.org/downloads/ Guidelines\%20to\%20Authors_final.pdf). Using the above abstract as an example, the revised abstract shown below serves as a clear summary containing objectives, results, and a brief conclusion. It is now shorter and contains about 200 words. In this suggested revision, we deleted comments related to Zhejiang since the main point of the study was a comparison of Clinical Engineering practice between Beijing and the United States.

We report a new clinical engineering (CE) benchmarking comparison between Beijing (11 hospitals) and the United States (270 acute care hospitals) that was completed in 2018. First, comparisons were made with hospital data such as patient discharges, patient days, equipment quantity and cost, and operating costs. The CE benchmarking comparison was made in 3 categories: (a) operations, (b) finance, and (c) staffing/productivity. These comparisons showed the following: (1) Beijing hospitals have a bit lower equipment than the United States; (2) the total CE expense/ total hospital operating expense ratio is around $1 \%$ in both Beijing and the United States; however, the total CE expense/operating beds and total CE expense/ equipment cost are still lower in Beijing than in the
United States; and (3) the CE Full Time Equivalents amount relative to both equipment amount and total hospital operating expense is similar in Beijing and the United States. Some of the differences detected are likely caused higher length of stay in China than in the United States, lower wages and living costs in China, and different healthcare delivery methods in these countries. Overall, these results confirm the outstanding progress and level of excellence of CE in China.

The abstract should be composed at the very end of your writing since it includes a summary of the elements of your work such as the research problem and objectives, the methods, key results, and the main conclusion.

\section{Introduction Section}

The primary purpose of the Introduction section of a research paper or report is to provide background and place the specific context of the work from the perspective of a more general issue or problem. A common mistake in writing an introduction is to provide too much detail in reference or methods. ${ }^{1,11}$

Elements of the Introduction section are:

- Background

- importance of the problem

- what the objectives of the study

- what is the existing state of knowledge of this topic - mini-review that traces the development of the problem and summarizes its current state

- how was the study conducted and why

- a preliminary indication of the outcome or conclusion of the report

Here we provide an Introduction section from two articles that discuss issues related to alarms in intensive care units. The presentation in Example A is very thorough, but perhaps over extensive in the literature review citations. The presentation in Example B is more descriptive, does not provide literature citations, and is perhaps more suitable for a magazine rather than a scientific journal.

\section{Example $\mathbf{A}^{12}$}

"With the development of medical technology, clinical alarms from diverse medical devices, which are explosively increasing, are becoming a new issue in intensive care units (ICUs). Medical device (clinical) 
alarms, which were designed to draw medical staff's attention when a patient's conditions goes beyond the proper range, are causing a new alarm hazard problem.1 According to previous studies, there were no more than 6 types of alarms from one critically ill patient in 1983; however, there were at least 40 types of clinical alarms in $2011 .^{1}$

Excessive clinical alarms may cause an alarm hazard, which includes inappropriate application of alarms, alarm fatigue, and the application of a uniform alarm range to every patient. ${ }^{2}$ While defects of devices threatened patient safety in the past, alarms indiscriminately generated by the explosive increase in the number of medical devices now threaten their safety. Reports on safety accidents related to the diversity of medical device alarms have raised awareness of the clinical alarm hazard. In 2002, 65\% of 23 sentinel events were related to dysfunction and disuse of alarm devices and inappropriate alarm setting. ${ }^{3}$ Five-hundred sixty-six deaths related to the monitoring of device alarms ${ }^{4}$, severe burns due to neglect of alarms from hyperthermic machines ${ }^{5}$ and hypoxic brain damage ${ }^{6}$ were also reported. In 2012, alarm hazard was ranked first among ten types of medical technology hazards in the United States. ${ }^{2}$

Ambient noises, including clinical alarms in ICUs were estimated to be more than $80 \mathrm{~dB}$, which is close to the noise level generated by a pneumatic drill in an operating room. ${ }^{7}$ In addition to the noise problem caused by alarms, ICU nurses may have difficulty in distinguishing alarms for urgent intervention from others since different device manufacturers use different types of alarms. For example, they need to differentiate alarms for replacing the syringe of an infusion pump from those for a life-threatening emergency when they hear both types of alarms. ${ }^{8}$ ICU nurses were found to have difficulty in differentiating more than 6 different alarms ${ }^{1,9}$ and could differentiate no more than 9-14 out of 23 alarms on average. ${ }^{10}$

In one study, medical staff members were repeatedly exposed to an average of 771 patient monitor alarms per patient per day. ${ }^{11}$ Medical staff overexposed to alarms may experience a decrease in concentration, become careless, and commit mistakes. Moreover, overexposure may make medical staff less sensitive to alarms and may cause them to cope improperly with significant alarms that can affect patients' safety. ${ }^{12}$ The literature suggests that excessive medical device alarms may cause nurses to feel alarm fatigue., ${ }^{73,14}$

Alarm fatigue occurs when medical staff are overwhelmed by excessive clinical alarms ${ }^{2}$; in particular, false (positive) alarms, inappropriate alarms-setting ranges, and the overuse of patient monitors act as principal factors that cause alarm fatigue. ${ }^{7,14}$ Of these, the most problematic factor is false alarms: frequent false alarms may produce the 'cry wolf' effect and may cause nurses to regard significant alarms as false and thus fail to respond properly. It may also make an alarm system less reliable and may cause nurses not to use alarm devices. ${ }^{14,15}$ It is therefore essential to effectively manage medical device alarms and develop good interventions that can reduce false alarms. Since 2010 , standardized prevention has been suggested on the basis of various studies on how to conceptualize and reduce alarm fatigue ${ }^{16,17,18,19}$ and basic research on nurses' recognition of clinical alarms and on the obstacles to their alarm management ${ }^{16,17}$ in the United States. On the contrary, in Korea, little research has been conducted on medical device alarms. Medical device alarm hazard and alarm fatigue are novel concepts, and the Korean Society for Patient Safety established in 2013 has just posted a foreign article introducing the concept of clinical alarms. ${ }^{20}$

This study aimed to investigate the current status of medical device alarms in ICUs, where medical devices equipped with an alarm function are most frequently used, to determine nurses' recognition of and fatigue in relation to alarms, and to identify obstacles to alarm management. This information will provide basic data that could help create a safe hospital environment."

\section{Example $\mathbf{B}^{13}$}

"More and more medical devices are being used throughout healthcare institutions with an increasing variety of alarm-related features. Alarms are used to warn of disconnected monitoring electrodes and ventilator breathing circuits. They can alert clinical staff when important measurements like oxygen saturation exceed safe limits or when a dangerous situation occurs like air entering the IV line for an infusion pump. Most of the time, clinical alarms work well and serve, literally, 
as a life-saving technology. However, for many devices, alarms can be confusing or can create confusion, for example from false positive events. For some devices, alarm settings can be adjusted outside of safe limits or the alarms can be completely defeated. As a result of these and other problems, deadly and life-threatening alarm-related incidents continue to occur. While the development of broad systematic improvements for how clinical alarms are designed and used are necessary to achieve the ultimate goal of reliable clinical alarm performance, the results are years away. This article focuses on ways that clinical engineers can have a much more direct and immediate impact on minimizing clinical alarm risk in their institutions. These include establishing safety criteria for alarms during the device selection process, performing alarmrelated safety audits to identify specific areas of risk with existing alarms and systems, helping to establish alarm setting and response protocols, and supporting the training of clinical staff on the proper operation and use of medical devices with clinical alarms."

\section{Methods Section ${ }^{11}$}

The Methods section is where the procedures used in the study are described and a description of how data were collected is given. In providing information on the methods used, one doesn't need to give a detailed recipe of every detail but sufficient information for those who are "skilled in the art"14 to understand and evaluate the procedures. Where possible, a method used that was described elsewhere in the literature should also be indicated and cited by reference.

The format of a Methods section depends somewhat on the type of investigation. For an article that is primarily of a survey nature, such as the performance evaluation of a system such as "alarms in intensive care" as mentioned above, the methods section would include how survey data were obtained. For articles that are experimental in nature the methods section usually describes materials and procedures.

The example below ${ }^{15}$ illustrates a thorough description of a Methods section for an experimental research paper. It provides adequate information on describing the source and characterization of materials used in the study (MATERIALS). Then a clear description of how the data were collected and analyzed (ASSESSMENT OF AEROSOL OUTPUT and IMAGE ANALYSIS OF AEROSOL PLUMES). Then a thorough explanation of the evaluation of the reliability of the data (STATISTICAL ANALYSIS OF RESULTS).

\section{Materials}

This study was performed using the following pharmaceutical preparations:

(1) the CFC-free MDI Airomir." This preparation contains albuterol sulfate as the active ingredient and nominally releases $200 \chi 100$-pg doses of albuterol. It also contains the propellant HFA-134a and oleic acid and ethanol as inactive ingredients.

(2) The multidose DPI Terbasmin Turbuhaler,b which nominally contains $200 \times 500$-pg doses of terbutaline sulfate.

(3) The CFC-propelled MDI Terbasmin Inhalacion,c which nominally contains $400 \times 250$-pg doses of terbutaline; it also contains a mixture of three $\mathrm{CFC}$ propellants (1:2:1 of CFC 11:12:114 mixture) and other inactive ingredients. The two pharmaceutical preparations of terbutaline were obtained from commercial sources.

\section{Assessment of aerosol output}

Experiments were conducted in industrial thermostated $\left(2{ }^{\circ} \mathrm{C}\right)$ chambers" at room $\left(22^{\circ} \mathrm{C}\right)$, cool $(0$ $\left.{ }^{\circ} \mathrm{C}\right)$, or cold $\left(-10{ }^{\circ} \mathrm{C}\right)$ temperatures. Three groups of fully assembled HFA-134a inhaler devices (canister, mouthpiece) with different initial contents (full, onehalf full, and one-fifth full, titrated by 0,100 , or 160 actuations, respectively) were stored in the thermostated chambers hours before the standardized set of nebulizations. The assembled containers were then shaken for approximately 30 seconds, and the valve was actuated at intervals of 10 seconds in an inverted position. DPI devices were inserted via a mouthpiece adapter into an inhalation simulation machine formed by a glass bulb and tube connected to a vacuum pump. The inhalation flow rate necessary to activate the DPI was provided by turning the pump on for five seconds and adjusting the suction pressure to obtain a flow rate of $60 \mathrm{~L} / \mathrm{mhv} 1$, which is appropriate for the Turbuhaler system. Forty actuations were performed with each pharmaceutical preparation to reduce potential minor variabilities between individual measures. To avoid the thermal influence of the operators' hands 
during actuation, the operators wore thick latex gloves stocked with the inhalation devices inside the chambers. The canisters were weighed at $25^{\circ} \mathrm{C}$ using a Mettler precision balance (readability $10 \mathrm{~g}$, accuracy defined as 100 [displayed weight - true weight]/true weight ranged from $3 \%$ to $5 \%$ ). Each container was weighed before and after its particular set of actuations, and the net amount of aerosol emitted was determined by subtracting final weights from the initial weights of the canisters; the results were expressed in grams or milligrams. Results are also expressed as a percentage of the amount of aerosol discharged in cool or cold conditions with respect to that expelled under control conditions $\left(22^{\circ} \mathrm{C}\right)$.

\section{Image analysis of the aerosol plume}

The propelled aerosols from HFA-134a and CFCcontaining MDIs were visualized by a sequence of highspeed dark-field photographs taken of three actuations at $22{ }^{\circ} \mathrm{C}$ and $-10{ }^{\circ} \mathrm{C}$. Representative pictures of a fully formed aerosol plume were digitized by scanning analysis; the captured image was then improved, transferred to the appropriate format,' and processed using image analysis software.' Isodensity lines were defined with this software in the digitized image of the aerosol cloud (i.e., lines connecting points of equal gray intensities [from 0 to 220 arbitrary units]). The aerosol plume formed after activation of a DPI in the inhalation simulation machine was observed only by visual inspection, since the quality of photographs was poor due to light reflecting brightly from the glass of the apparatus.

\section{Statistical analysis of results}

Data are expressed as mean SEM. The data on experimental groups passed the Kolmogorov-Smirnov normality test; hence, statistical analysis was performed using ANOVA, followed by the Bonferroni multiple comparison test. k Linear regression analysis was conducted using the same software. Significance was defined as $\rho$ less than 0.05 .

\section{Results Section}

Typically, the Results section provides information that was gathered during the study. Of course, not all the data would be selected for publication, but the studies that are pertinent to the thrust of the project. Some comments, explanation, or discussion should be provided with each element of the results.

The text in the Results section should act as a tour guide, leading your reader from item to item (every figure or graph must be cited in the text and in numerical order), and drawing attention to the highlights, especially to those that will be important in making conclusions.

There are several keys to writing a good results section. These include:

(1) Presentation of the results in an orderly sequence, following the sequence of the Methods section when feasible.

(2) If tables and figures will be used to summarize your data, then construct these first and use them as a basis for writing the Results sections. Make sure the main points of explanation and interpretation are given prominence in the first sentence of each paragraph.

(4) Avoid redundancy in the text and only cite representative data from the tables and figures. Do not repeat but summarize the information in tables and figures.

(5) Avoid vague references to tables and figures in the text.

\section{Example:}

BAD: Results of the survey of nurses are shown in Table 1. GO0D: A high percent of alarm notifications were ignored by nurses in the ICU setting, see Table $1 .^{15}$

TABLE 1. An example of Medical Equipment Management Plan (MEMP) inventory inclusion criteria using patient risks and mission criticality for planning preventive maintenance (PM) and safety and performance inspection (SPI) activities.

\begin{tabular}{lcccc}
\hline & & \multicolumn{3}{c}{ Patient Risks (Listed in the EP)* } \\
\cline { 3 - 4 } Mission criticality & Critical & High & Medium & Low \\
& Important & Include & Include & Include \\
& Necessary & Include & Optionalt & Exclude \\
& Exclude & Exclude \\
\hline${ }^{* E P}=$ Element of Performance, from the Joint Commission on Accreditation of Healthcare Organizations' published \\
accreditation standards. \\
tIndicates that some of the equipment may benefit from scheduled services, depending on the fallure modes and \\
effects analyses or other studies conducted by the organization.
\end{tabular}

(6) Avoid repeating a description of the methods in the Results section.

(7) Avoid discussion of conclusions in the Results section. In other words, present the facts but save interpretation of the significance of the results for the Discussion/ Conclusion section. 
Whenever appropriate, the results of the study should be summarized in tables and/or graphs. Readers may look at tables or graphs even before reading the text and would like to understand these without searching back and forth to the body of the text. The design of tables and graphs are quite critical to helping the reader fully understand the quality of the data and how the data supports the conclusion of the report. ${ }^{12}$

Some good and bad examples and suggestions for best practices for tables and graphs are given in a pdf from $M I T .{ }^{16}$ A recent article from the British Journal of Dermatology ${ }^{8}$ illustrates excellent examples of tables and graphs.

Above is an example of a well-organized Table 1. The title is a concise sentence. The column headings and subheadings are clear enough to make the data understandable without having to look at the text. The footnote gives enough detail to make the data understandable without going into experimental detail. ${ }^{18}$

Graphs are used to present data in an organized way, not to dress it up. One should not use both graphs and tables for the same data. Line graphs are best for data that show pronounced trends, while bar and dot charts are better to show items with different values. Consider the impact from the use of colors versus black and white especially if the publication cannot accommodate the use of color. In most of the on-line publications like the Global Clinical Engineering Journal this is not a problem. One should provide textual context for graphs, indicating how the graph advances, summarizes your discussion, and supports and clarifies your conclusions. Graphs should be as self-explanatory as possible. This allows the reader to scan through the article and get the key messages without needing to read the text in detail.

Fig.3 (next column) is an example of a poor graph. ${ }^{17}$ The symbols AE, AV, EE, and EP are not defined in the legend of the graph, nor is the meaning of the term Microprocess explained.

Fig.5 (next column) is an example of a good graph. The lettering is large enough to withstand photographic reduction. The caption is concise and provides information pertinent to the discussion, tolerance of error bars are provided. $^{20}$

Often data can be presented in either a graph or a table. The choice depends on which better informs the reader. In the example below, data are provided for the

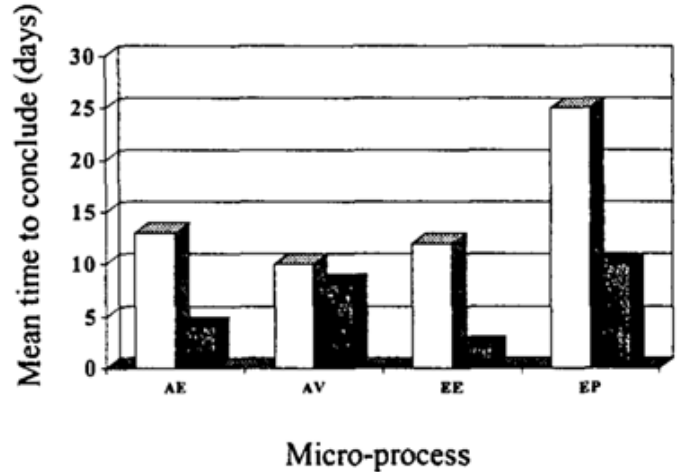

Fig. 3. Elapsed time (including non-working days) to solve micro-processes. Micro-processes are defined in Table I. Clear and shaded bars refer to 1997 and 1999 data, respectively.

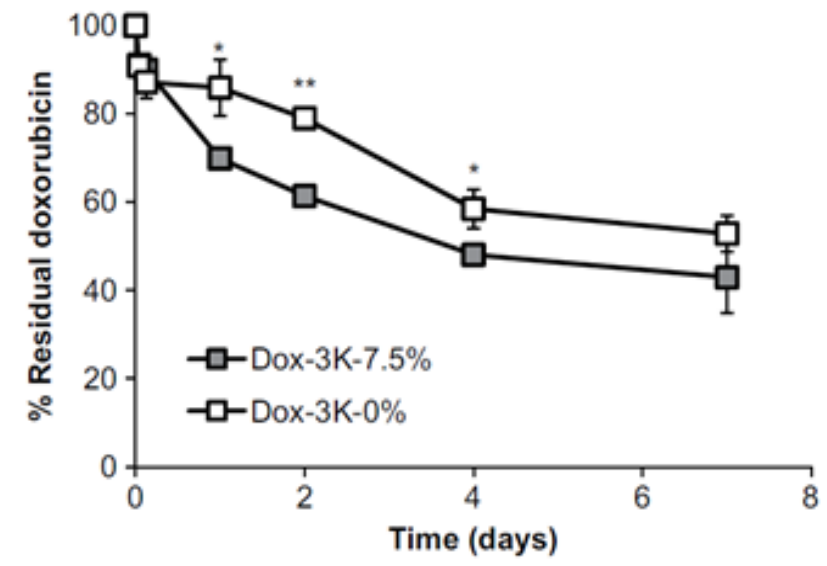

Fig. 5. In-vitro release kinetics of doxorubicin from PLGA microparticles, Doxorubicin remaining in the particles at each time point was plotted vs, incubation time. The data represent the average results of 3 independent batches. Error bars are standard deviations and not seen in some data points as they are smaller than the symbols. " $(p<0.05)$ and ${ }^{*}(p<0.01)$ indicate statistical difference between Dox-3K-7.5\% and Dox-3K-0x at each time point.

comparison of an implanted glucose monitor (FreeStyle Libre) with blood-sample technique (YSI). Trends across different levels of blood glucose are much clearer in the bar graphs than in the published table below. ${ }^{19}$

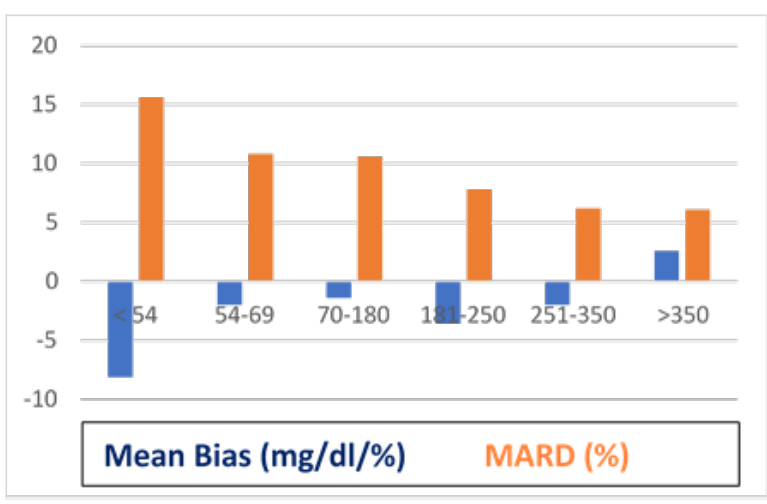


Table 1: Performance characteristics of FreeStyle

Libre system with new glucose algorithm

\begin{tabular}{|c|c|c|c|c|c|c|}
\hline $\begin{array}{c}\text { CGM } \\
\text { Glucose } \\
\text { Level }^{1} \\
(\mathrm{mg} / \mathrm{dL})\end{array}$ & $\begin{array}{c}\text { CGM- } \\
\text { YSI } \\
\text { Pairs }\end{array}$ & $\begin{array}{c}\text { Within } \\
\pm 15 \\
\mathrm{mg} / \mathrm{dL} \\
/ 15 \%\end{array}$ & $\begin{array}{c}\text { Within } \\
\pm 20 \\
\mathrm{mg} / \mathrm{dL} \\
/ 20 \%\end{array}$ & $\begin{array}{c}\text { Within } \\
\pm 40 \\
\mathrm{mg} / \mathrm{dL} \\
/ 40 \%\end{array}$ & \begin{tabular}{|c|} 
Mean \\
bias*, \\
$\mathrm{mg} / \mathrm{dL}$ \\
$/ \%$ \\
\end{tabular} & $\begin{array}{c}\text { MARD } \\
(\%)\end{array}$ \\
\hline$<54$ & 60 & .7 & 5.0 & 8.3 & -8.1 & 15.6 \\
\hline $54-69$ & 3311 & .5 & 5.1 & 9.3 & 2.0 & 10.8 \\
\hline $70-18$ & 7944 & .4 & 6.5 & 9.1 & 1.4 & 10.6 \\
\hline $181-250$ & 3038 & .1 & 5.0 & 99.9 & -3.6 & 7.8 \\
\hline $251-350$ & 3849 & 93.7 & 7.7 & 100.0 & -2.0 & 6.2 \\
\hline$>350$ & 652 & 94.5 & 8.6 & 99.8 & 2.0 & 6.1 \\
\hline All & 18856 & 86.0 & 92.8 & 99.6 & -1.7 & 9.2 \\
\hline
\end{tabular}

${ }^{1}$ System dynamic range is $40-500 \mathrm{mg} / \mathrm{dL}$

* Difference in $\mathrm{mg} / \mathrm{dL}$ for blood glucose values

$<70 \mathrm{mg} / \mathrm{dL}$ and relative difference in $\%$ for blood glucose values $>=70 \mathrm{mg} / \mathrm{dL}$

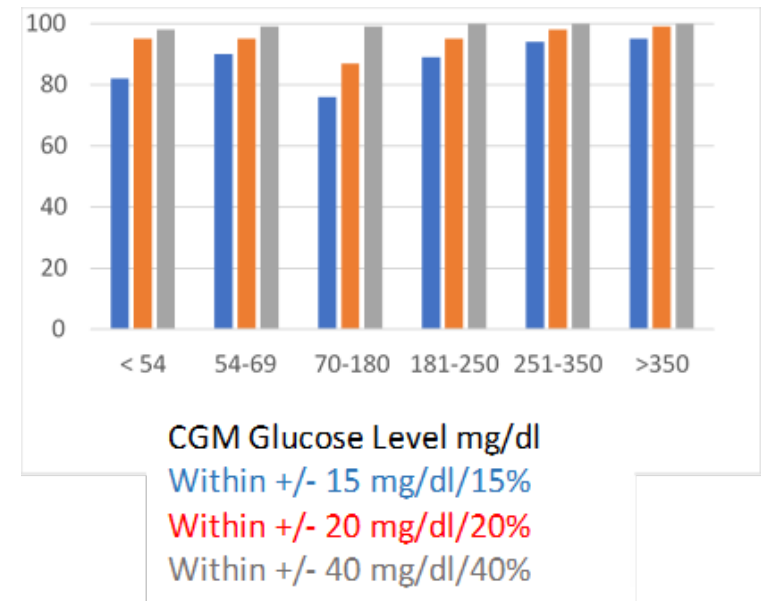

\section{Discussion and Conclusion Section}

The main purpose of this section is draw conclusions from the data gathered in the study and perhaps to compare the results to previous similar studies. Here you provide an interpretation of your results and answers the study question. You can suggest further work to be done and review the literature again as it now can shed more insight on the subject of the paper. ${ }^{21}$ Here are some guidelines for structuring this section.

1. Summarize key findings and interpret the results
2. Compare with other studies

3. Generalize results if appropriate

4. Speculate on implications of the study

5. Point out any limitations of the study

6. Suggest possible follow-up studies

7. Succinctly list your conclusions

The table below summarizes the elements and suggestions for submitting a paper to the Global Clinical Engineering Journal:

\section{Title}

Concise \& descriptive

All words capitalized except articles and prepositions

Abstract
Describes problem \& states objectives/hypotheses
Describes technique(s) used \& avoids experimental detail
Reports most significant results
Concluding statement

\section{Introduction}

Demonstrates good clinical engineering insight, understanding, \& accuracy

Reviews \& interrelates relevant scientific literature

Cites literature correctly using name-year or citation-sequence convention

Flow of ideas - starts broadly, then leads to a specific topic Ends with clearly \& concisely stated 1-3 hypotheses/objectives

\section{Methods}

Written in the third person and past tense

Concise but complete

Accurately describes what was done, without giving instruction Statistics and quantitative methods are explained Literature cited (if appropriate)

\section{Results}

Results clearly and accurately explained

Statistical output appropriately noted

All relevant tables and figures cited appropriately

\section{Discussion and conclusions}

Clearly addresses each hypothesis/objective - supported or rejected?

Demonstrates good insight and mastery of relevant ideas Compares results to previous studies (cite relevant literature) Explains unexpected results (e.g., provides alternative hypotheses)

Describes or suggests future experiments

List your conclusions and possible impact from the results 


\section{Acknowledgments}

Be professional (avoid being "gushy" or overly flippant)

\section{Literature Cited}

Precisely and consistently follows style of Global CE Journal All citations noted in the manuscript are included in the Literature Cited list

Each reference listed has been cited at least once in the manuscript

\section{Tables}

Tables appear after Literature Cited section

Tables are numbered consecutively, starting with Table 1

Titles are sufficiently clear and concise

Double-spacing used throughout the table

Columns of numbers aligned by decimal point using decimal tabs

\section{Figures}

Horizontal axis $=$ independent variable, vertical axis $=$ dependent variable

Axes clearly labeled

\section{SUBMISSION TO GLOBAL CLINICAL ENGINEERING JOURNAL}

Manuscripts submitted to the Global Clinical Engineering Journal are subjected to the initial review by the Editorin-Chief for the purpose of identifying overlap between the manuscript and the mission of the Journal and for identifying the most appropriate editors to be assigned for the double-blind review process. The complete publication process is posted on the Journal website (http:// www.globalce.org/downloads/Flowchart_GlobalCE.pdf) and is presented below.

This process provides for a quality review that is fair and timely. It helps the authors receive constructive feedback on how to improve their submission. It also facilitates the posting of individual accepted manuscripts immediately or even prior to the scheduled publishing of the next issue of the Journal. Now, we encourage you to begin working on your manuscript and gain recognition for your work.

\section{CONFLICTS OF INTEREST STATEMENT}

The authors declare that there is no conflict of interest.

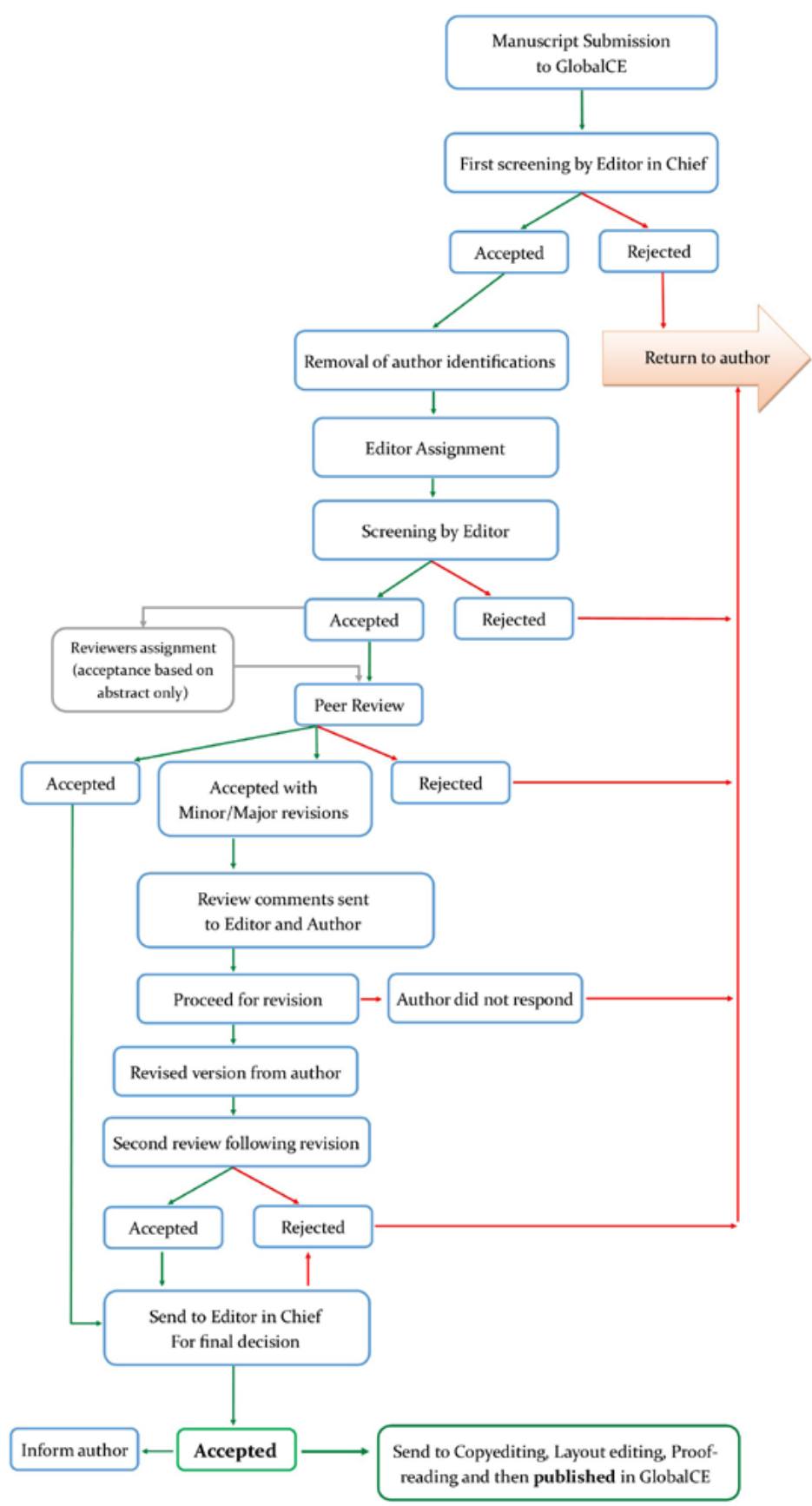

\section{REFERENCES}

1. Lang TA. Writing a better research article. J Pub Health Emergency. December 2017;1. Available at: http://jphe. amegroups.com/article/view/4265/5102.

2. King L. Preparing better graphs. J Pub Health Emergency. January 2018;2(1). Available at: http://jphe.amegroups. com/article/view/4288/5126. 
3. Liu W. Preparing better tables. J Pub Health Emergency. January 2018;2(1). Available at: http://jphe.amegroups. com/article/view/4327/5152.

4. Mack CA. How to Write a Good Scientific Paper. Society of Photo-Optical Instrumentation Engineers (SPIE). [Internet]. ISBN 9781510619135, 2018, Washington, USA. Available at: https://spie.org/samples/9781510619142.pdf.

5. Kanamala N. Progressing toward the application of artificial intelligence for medical equipment replacement in Canadian hospitals-An idea from the Biomedical Engineering Department at Northern Health. J Clin Engineer. December 2019:45(2)128-32. Available at: https://www.researchgate. net/publication/340053463_Progressing_Toward_the_Application_of_Artificial_Intelligence_for_Medical_Equipment_ Replacement_in_Canadian_Hospitals_- An_Idea_From_the_ Biomedical_Engineering_Department_at_Northern_Health.

6. Wang B and Deng W. Benchmarking comparison between Beijing and American Hospitals. J Clin Engineer 2020;45(1):31-8. Available at: https://insights. ovid.com/clinical-engineering/jceng/2020/01/000/ benchmarking-comparison-beijing-american-hospitals/11/00004669.

7. Michel E, Entenmann A, and Michel M. Pulse spectrophotometric determination of plasma bilirubin in newborns. 2016; Int J Biomed Clin Engineer 2016;5(1). Available at: https://www.igi-global.com/gateway/article/145164.

8. Ubriani R, Smith N, and Katz KA. Reporting of study design in titles and abstracts of articles published in clinically oriented dermatology journals. Br J Dermatol 2007;156:557-9.

9. Wong HL, Truong D, Mahamed A, et al. Quality of structured abstracts of original research articles in the British Medical Journal, the Canadian Medical Association Journal and the Journal of the American Medical Association: a 10-year follow-up study. Curr Med Res Opin 2005;21:467-73.

10. University of Wisconsin, La Crosse. Research Manuscripts. [Internet]. Available at: http://websites.uwlax.edu/biology/ResearchManuscripts.html.

11. University of Saskatchewan. Writing a Paper or Lab Report in Scientific Format, Appendix 18. [Internet]. Available at: http://www.usask.ca/biology/kaminskyj/342/lab/ Biol342_04lab/Ap18_Lab_rept.pdf.

12. Cho OM, Lee YW, Kim H, Insook C. Alarms in intensive care units: perceived obstacles of alarm management and alarm fatigue in nurses. Healthcare Informat Res 2016 Jan;22(1):46-53.
13. Keller J Clinical Engineering's role in managing clinical alarm risk, biomedical instrumentation \& technology. AAMI January 2006;40(1). Available at: https://www.aami-bit. org/doi/full/10.2345/0899-8205\%282006\%2940\%5B6 4\%3ACERIMC\%5D2.0.C0\%3B2

14. What is a Person Having Ordinary Skill in the Art? [Internet]. Upcounsel legal platform 2020. Available at: https://www. upcounsel.com/person-having-ordinary-skill-in-the-art.

15. Ramon M. Gustavo J, Torrejon JM. Influence of storage at low temperatures on the aerosol output from metered-dose and dry-powder inhalation devices. J Pharm Technol January 2000;16(1):12-7. Available at: https://journals.sagepub. com/doi/10.1177/875512250001600105

16. MIT.edu. Illustrations: Tables and Graphs, Meeting 3. [Internet]. Available at: http://web.mit.edu/7.021/www/ lectures/TablesGraphs_MO.pdf.

17. Bassani JWM, Rocha LS, Luders ML, and Bizinotto WJ. Micro-Process Based Management of Medical Equipment Maintenance. Proceedings of the Second Joint 24th Annual Conference and the Annual Fall Meeting of the Biomedical Engineering Society, Engineering in Medicine and Biology, Houston, TX, USA, October 2002, pp. 1942-1943 vol.3. Available at: https://ieeexplore.ieee.org/abstract/ document $/ 1053105$

18. Binseng Wang, Emanuel Furst, Ted Cohen, Ode R. Keil, Malcolm Ridgway, and Robert Stiefel: Medical Equipment Management Strategies. Biomedical Instrumentation \& Technology, AAMI, May 2006, Vol. 40, Issue 3, pp. 233-237, https://www.aami-bit.org/doi/full/10.2345/i0899-820540-3-233.1, (last visited March 23, 2020).

19. Karinka SA, Bailey TS, Brazg RL, et al: Clinical diabetes/ therapeutics, 910-P: improved accuracy of 14-day factorycalibrated FreeStyle Libre system with new glucose algorithm. Diabet J, Am Diabet Assoc June 2019;68 (Supplement 1), Poster Presentations. Available at: https://diabetes. diabetesjournals.org/content/68/Supplement_1/910-P

20. Yang Y, Bajaj N, Xu P, et al. Development of highly porous large PLGA microparticles for pulmonary drug delivery. J Biomaterials April 2009;30(10):1947-53. Available at: https://www.sciencedirect.com/science/article/pii/ S0142961208010181?via\%3Dihub,

21. Bates College, Department of Biology. How to Write a Paper in Scientific Journal Style and Format. [Internet]. Available at: https://www.bates.edu/biology/files/2010/06/Howto-Write-Guide-v10-2014.pdf. 